\title{
Dampak Ekonomi dan Kesehatan pada Konsumen Rokok Elektronik di Kota Bandung
}

\author{
Estro Dariatno Sihaloho ${ }^{1}$, Irlan Adiyatma Rum² \\ 'Departemen Ilmu Ekonomi Fakultas Ekonomi dan Bisnis Universitas Padjadjaran, Jln. Dipati Ukur No. 35, Bandung, \\ 40132, Jawa Barat, Indonesia \\ ${ }^{2}$ Departemen Ilmu Ekonomi Fakultas Ekonomi dan Bisnis Universitas Padjadjaran, Jln. Dipati Ukur No. 35, Bandung, \\ 40132, Jawa Barat, Indonesia \\ estro.sihaloho@unpad.ac.id
}

\begin{abstract}
A B S T R A C T
Consumers of conventional cigarettes have begun to switch to using electronic cigarettes. Having different characteristics of these two kinds of cigarettes make the different health and economic effects to consumers. This study uses Ordinary Least Square (OLS) method to analyze the influence of electronic cigarette usage on conventional cigarette usage in Bandung in 2017. This study used 200 respondents of electronic cigarette users. This study uses the amount of conventional cigarette consumption after using electronic cigarette per day $(Y)$ as the dependent variable. For independent variables, this study uses conventional cigarette consumption before using electronic cigarette per day $\left(X_{1}\right)$, total liquid of electronic cigarette consumption per month $\left(X_{2}\right)$, monthly electronic cigarette expenditure $\left(X_{3}\right)$, and respondent's perception whether using electronic cigarette more healthy $\left(X_{4}\right)$. Regression results showed that $X_{1}$ and $X_{4}$ have significant effect on $Y$. The increase of 1 stem of conventional cigarettes consumption before using electronic cigarette per day $\left(X_{1}\right)$ will increase the consumption of conventional cigarettes after using electronic cigarette per day $(\mathrm{Y})$ of 0.1618005 stem. While with the respondent's perception that using electronic cigarette is healthier ( $\left.X_{4}\right)$ will reduce the consumption of conventional cigarettes $(Y)$ as much as 5.169504 stems..
\end{abstract}

\section{Keywords:}

Conventional Cigarettes, Electric Cigarettes, Economics, Health

\begin{abstract}
A B S T R A K
Konsumen rokok konvensional sudah mulai beralih menggunakan rokok elektronik. Memiliki karakteristik yang berbeda menjadikan efek kesehatan dan ekonomi yang dirasakan konsumen juga berbeda. Penelitian ini menggunakan metode Ordinary Least Square (OLS) yang bertujuan untuk menganalisis bagaimana pengaruh penggunaan rokok elektronik terhadap penggunaan rokok konvensional di Kota Bandung pada tahun 2017. Penelitian ini menggunakan responden sebanyak 200 pengguna rokok elektronik. Penelitian ini menggunakan jumlah konsumsi rokok konvensional sesudah menggunakan rokok elektronik per hari $(\mathrm{Y})$ sebagai variabel dependen. Sedangkan untuk variabel independen, penelitian ini menggunakan jumlah konsumsi rokok konvensional sebelum menggunakan rokok elektronik per hari ( $\left.\mathrm{X}_{1}\right)$, jumlah konsumsi cairan rokok elektronik per bulan (X2), jumlah pengeluaran rokok elektronik per bulan (X3), dan persepsi responden apakah menggunakan rokok elektronik lebih sehat (X4). Hasil regresi menunjukkan bahwa terdapat 2 variabel yang berpengaruh signifikan yaitu $\mathrm{X}_{1}$ dan $\mathrm{X}_{4}$. Kenaikan 1 batang konsumsi rokok konvensional sebelum menggunakan rokok elektronik per hari (X1) akan meningkatkan konsumsi rokok konvensional sesudah menggunakan rokok elektronik per hari $(Y)$ sebesar 0.1618005 batang. Sedangkan persepsi responden menggunakan rokok elektronik lebih sehat (X4) akan mengurangi konsumsi rokok konvensional (Y) sebanyak 5.169504 batang.
\end{abstract}

Kata Kunci:

Rokok Konvensional, Rokok Elektronik, Ekonomi, Kesehatan

\section{PENDAHULUAN}

Indonesia merupakan salah satu negara dengan tingkat konsumen rokok konvensional tertinggi di dunia. Survey WHO pada 31 Desember 2016 menunjukkan bahwa prevalansi pengguna rokok pada orang dewasa laki-laki adalah sebesar $64.9 \%$ sedangkan prevalansi pengguna rokok pada orang dewasa perempuan sebesar $2.1 \%$ (WHO, 2017).
Prevalansi pengguna rokok pada anak muda lakilaki juga cukup tinggi dengan prevalansi sebesar $21.4 \%$ dan anak muda perempuan sebesar $1.5 \%$ sedangkan persentase pengguna rokok berusia muda dibandingkan dengan keseluruhan pengguna rokok di Indonesia adalah sebesar $11.5 \%$ (WHO, 2017).

Merokok memiliki banyak dampak negatif 
terhadap kesehatan pengguna rokok. Rokok merupakan faktor utama yang menyebabkan terjadinya osteoporosis, kebutaan, impotensi, kehilangan gigi, diabetes, mengurangi kesuburan, katarak, infeksi mata, asma, pennyakit jantung kardiovaskular, melemahnya fungsi paru-paru, berkurangnya pertumbuhan paru-paru, dan aterosklerosis (Egbe, Petersen, \& Weitz, 2016). Dengan banyaknya penyakit yang akan ditimbulkan dengan merokok maka pasti akan mengeluarkan biaya yang tidak sedikit untuk pengobatan. Selain kerugian kesehatan dan kerugian ekonomi dari penyakit yang ditimbulkan, konsumen harus mengeluarkan biaya yang tidak sedikit untuk membeli rokok. WHO melaporkan bahwa harga rata-rata rokok per bungkus (20 batang rokok) paling murah di Indonesia adalah $\mathrm{Rp}$ 5.833 dengan merek Menara 9 dan Pelangi. Sedangkan harga rata-rata rokok per bungkus paling mahal adalah Marlboro dengan harga sebesar Rp 28.333 dengan isi 20 batang per bungkus. Merek rokok yang paling banyak terjual di Indonesia adalah Gudang Garam dengan harga rata-rata sebesar $\mathrm{Rp}$ 21.666. Harga rata-rata ini adalah harga yang dijual secara retail dan biasanya memiliki tingkat harga yang berbeda-beda di tiap pedagang retail (WHO, 2017).

Saat ini, banyak konsumen rokok konvensional yang mulai mendapatkan barang subtitusi yaitu rokok elektronik. Peralihan dari rokok konvensional ke rokok elektronik dilakukan terutama oleh anak muda. Salah satu negara yang memiliki peningkatan jumlah konsumen rokok elektronik adalah Amerika Serikat. Penggunaan rokok elektronik di anak muda di Amerika Serikat sudah menjadi salah satu isu kesehatan publik yang utama. Dalam rentang dari tahun 2011 hingga tahun 2015, penggunaan rokok elektronik mengalami peningkatan sebesar 900\% di antara siswa sekolah menengah atas (US Department of Health and Human Services, 2016). Sama dengan rokok konvensional yang memiliki resiko penyakit, penggunaan rokok elektronik juga memiliki kontribusi signifikan terhadap kematian yang berkaitan dengan kanker paru-paru (US Department of Health and Human Services, 2016).

Pengembangan alat pertama dari rokok elektronik dilakukan oleh apoteker yang berassal dari Cina yang bernama Hon Lik dan mendapatkan paten yang berisikan berbagai jenis rokok elektronik (Hon, 2013). Kemudian dengan mendapatkan dukungan dari investor China, pada tahun 2004 produk rokok elektronik ini diperkenalkan ke pasar China oleh perusahaan Ruyan (Sanford \& Goebel, 2014). Tingkat pengeluaran rokok konvensional dan rokok elektronik cukuplah berbeda. Untuk menggunakan rokok konvensional, konsumen cukup membeli rokoknya saja. Sedangkan konsumen rokok elektronik biasanya harus mengeluarkan biaya lebih besar untuk konsumsi di awal karena harus membeli perangkat rokok elektronik. Perangkat rokok elektronik terdiri dari baterai, kotak sebagai wadah menyimpan nikotin, elemen pemanas dan corong asap (US Department of Health and Human Services, 2016). Selain mengeluarkan dana untuk membeli perangkat awal, konsumen harus membeli cairan yang merupakan bahan kimia nikotin dan memiliki rasa. Terdapat berbagai alasan mengapa pengguna rokok konvensional beralih menggunakan rokok elektronik. Dua alasan yang paling sering dikemukakan oleh konsumen rokok elektronik adalah agar responden berhenti menggunakan rokok konvensional dan responden merasa penggunaan rokok eletronik lebih sehat. Hasil survey yang dilakukan di Amerika Serikat menunjukkan bahwa mayoritas responden yaitu 65\% menggunakan rokok elektronik agar berhenti menggunakan rokok konvensional (Elter, 2010). Sedangkan dari sisi kesehatan, rokok elektronik dianggap lebih sehat dibandingkan rokok konvensional karena larutan yang digunakan untuk rokok elektronik hanya terdiri dari campuran air,zat penambah rasa, aroma tembakau dan senyawa lain yang tidak mengandung zat-zat yang umumnya terkandung pada rokok konvensional (William, Trtchounian, \& Talbot, 2010).

Global Adults Tobacco Survey pada tahun 2011 untuk Indonesia menunjukkan bahwa 10,9\% orang dewasa telah pernah mendengar mengenai rokok elektronik, tetapi hanya $0.3 \%$ dari mereka yang menggunakannya. Persentase pria sebesar $16.8 \%$ yang mendengar mengenai rokok elektronik lebih besar dibandingkan wanita yang hanya sebesar 5.1\%. Dari sisi umur, masyarakat yang memiliki umur 15-22 tahun mendengar mengenai rokok elektronik sebesar $14.4 \%$ lebih tinggi di bandingkan rentang umur $25-44$ sebesar $12.4 \%$. Survey juga menunjukkan bahwa 11.5 \% siswa SMP, 20.3\% siswa SMA, dan $29.4 \%$ mahasiswa perguruan tinggi telah pernah mendengar mengenai rokok elektronik. (Bam, Bollow, Berezhnova, Jackson-Moris, Jones, \& Latif, 2014). Jumlah masyarakat yang semakin banyak mendapatkan informasi mengenai rokok elektronik ini akan memiliki pengaruh terhadap jumlah pengguna rokok elektronik di Indonesia.

\section{METODE}

Penelitian ini menggunakan data primer yang didapatkan melalui proses wawancara. Wawancara 
dilakukan terhadap 200 orang responden yang merupakan pengguna rokok elektronik di Kota Bandung. Pengambilan data responden dilakukan terutama di kafe-kafe dan toko distributor cairan rokok elektronik yang tersebar di Kota Bandung. Pengambilan data primer dilakukan dari tanggal 3 Agustus 2017 hingga 15 September 2017. Penelitian ini menggunakan Ordinary Least Square (OLS) yang merupakan bentuk dari regresi sederhana. Untuk melakukan regresi sederhana, penelitian ini menggunakan STATA 12 dan menggunakan Excel untuk melakukan analisis lainnya. Model yang digunakan untuk dalam penelitian ini adalah :

$\mathrm{Y}=\alpha_{0}+\alpha_{1} X_{1}+\alpha_{2} X_{2}+a_{3} X_{3}+a_{4} X_{4}+e$

Dimana :

Y merupakan Jumlah Konsumsi Rokok Konvensional Sesudah menggunakan Rokok Elektronik/hari (Batang)

X1 merupakan Jumlah Konsumsi Rokok Konvensional Sebelum menggunakan Rokok Elektronik/hari (Batang)

X2 merupakan Jumlah Konsumsi Cairan Rokok Elektronik/Bulan (Botol)

X3 merupakan Jumlah Pengeluaran Rokok Elektronik/Bulan (Rupiah)

X4 merupakan Persepsi Apakah Menggunakan Rokok Elektronik Lebih Sehat?

(lya=1,Tidak=0)

\section{HASIL DAN PEMBAHASAN}

Data primer menggunakan hasil wawancara dari 200 responden menunjukkan hasil yang sangat bervariasi. Dari 200 responden yang diwawancara sebagian besar dari pengguna rokok elektronik tersebut adalah masyarakat yang memiliki pendidikan terakhir Akademi atau pun perguruan tinggi.

Tabel 1. Tingkat Pendidikan Terakhir Responden

\begin{tabular}{|c|c|c|}
\hline $\begin{array}{c}\text { Tingkat Pendidikan } \\
\text { Terakhir }\end{array}$ & $\begin{array}{c}\text { Jumlah } \\
\text { (Orang) }\end{array}$ & Persentase \\
\hline SLTP & 3 & $1.50 \%$ \\
\hline SLTA & 61 & $30.50 \%$ \\
\hline $\begin{array}{c}\text { Akademi/Perguruan } \\
\text { Tinggi }\end{array}$ & 136 & $68.00 \%$ \\
\hline
\end{tabular}

Sumber : Hasil Wawancara

Tabel 1 menunjukkan bahwa dari dari 200 responden yang di wawancarai tidak ada yang dibawah tingkat SLTP seperti lulusan SD atau tidak memiliki pendidikan. Yang merupakan lulusan SLTP juga hanya 3 orang atau sebesar $1.50 \%$. Hal ini menunjukkan bahwa kebanyakan besar pengguna rokok elektronik memiliki tingkat pendidikan yang cukup baik yaitu lulusan SLTA atau lulusan perguruan tinggi.

Tabel 2. Jenis Pekerjaan Responden

\begin{tabular}{|c|c|r|}
\hline Pekerjaan & $\begin{array}{c}\text { Jumlah } \\
\text { (Orang) }\end{array}$ & Persentase \\
\hline Karyawan & 54 & $27.00 \%$ \\
\hline $\begin{array}{c}\text { Pekerja } \\
\text { bebas/serabutan }\end{array}$ & 5 & $2.50 \%$ \\
\hline Pelajar/Mahasiswa & 118 & $59.00 \%$ \\
\hline Pengangguran & 1 & $0.50 \%$ \\
\hline Tidak menjawab & 2 & $1.00 \%$ \\
\hline Pekerjaan Lainnya & 20 & $10.00 \%$ \\
\hline
\end{tabular}

Sumber : Hasil Wawancara

Tabel 2 menunjukkan bahwa kebanyakan responden yang menggunakan rokok elektronik adalah pelajar atau mahasiswa yaitu sebanyak 118 orang atau sebesar 59\%. Di peringkat kedua adalah yang memiliki pekerjaan sebagai karyawan sebanyak 54 orang atau sebesar $27 \%$, diikuti pekerjaan lainnya sebanyak 20 orang atau 10\%. Hal ini menunjukkan bahwa di Kota Bandung, rokok elektronik lebih dikenal dan digunakan oleh pelajar atau mahasiswa. Data wawancara menunjukkan bahwa usia paling muda yang menggunakan rokok elektronik adalah 17 tahun dan yang paling tua adalah 47 tahun.

Tabel 3. Hasil Regresi

\begin{tabular}{|c|c|c|c|}
\hline \multicolumn{3}{|c|}{ Number of obs } & 200 \\
\hline \multicolumn{3}{|c|}{$F(4,195)$} & 18.20 \\
\hline \multicolumn{3}{|c|}{ Prob $>$ F } & 0.0000 \\
\hline \multicolumn{3}{|c|}{ R-squared } & 0.2718 \\
\hline \multicolumn{3}{|c|}{ Adj R-squared } & 0.2569 \\
\hline \multicolumn{3}{|c|}{ Root MSE } & 3.2438 \\
\hline $\mathbf{Y}$ & Coef. & Std. Err. $\quad$ t & $P>t$ \\
\hline $\mathbf{x 1}$ & 0.1618005 & $0.038286 \quad 4.23$ & 0.000 \\
\hline $\mathbf{x 2}$ & 0.5395122 & $0.446165 \quad 1.21$ & 0.228 \\
\hline$x 3$ & $-3.91 \mathrm{E}-06$ & $2.85 \mathrm{e}-06 \quad-1.37$ & 0.172 \\
\hline$\times 4$ & -5.169504 & $0.7130015 \quad-7.25$ & 0.000 \\
\hline cons & 5.691527 & $0.853902 \quad 6.67$ & 0.000 \\
\hline
\end{tabular}

Sumber : Pengolahan Data STATA 12

Pada tabel 3 diatas, setelah melakukan regresi menggunakan STATA 12 pada 200 responden dengan variabel Jumlah Konsumsi Rokok Konvensional Sesudah menggunakan Rokok Elektronik/hari (Batang), Jumlah Konsumsi Rokok 
Konvensional Sebelum menggunakan Rokok Elektronik/hari (Batang), Jumlah Konsumsi Cairan Rokok Elektronik/Bulan (Botol), Jumlah Pengeluaran Rokok Elektronik/Bulan (Rupiah), Persepsi Apakah menggunakan rokok elektronik lebih sehat

Dari tabel 3, kita dapat memperoleh persamaan regresi pada penelitian ini yaitu :

\section{$Y=5.691527+0.1618005 X 1+0.5395122 X_{2}$}

\section{$-0.00000391 X_{3}-5.169504 X_{4}$}

Dari hasil regresi di atas di dapatkan beberapa interpretasi yaitu konstanta $\boldsymbol{a}_{\mathbf{0}}$ sebesar 5.691527 menunjukkan bahwa responden akan mengkonsumsi rokok konvensional sebesar 5.691527 batang per hari tanpa adanya pengaruh dari variabel lainnya. $\boldsymbol{\alpha}_{1}$ sebesar 0.1618005 pada X1 menunjukkan bahwa jumlah konsumsi rokok konvensional sebelum menggunakan rokok elektronik akan berpengaruh positif dan signifikan sebesar 0.1618005 pada penggunaan rokok konvensional sesudah menggunakan rokok elektronik. Dengan adanya peningkatan jumlah konsumsi rokok konvensional sebesar 1 batang sebelum menggunakan rokok elektronik akan meningkatkan penggunaan rokok konvensional sebesar 0.1618005 sesudah menggunakan rokok elektronik.

$\boldsymbol{a}_{\mathbf{2}}$ sebesar 0.5395122 pada $\mathrm{X}_{2}$ menunjukkan bahwa jumlah botol cairan yang digunakan untuk rokok elektronik berpengaruh positif tetapi tidak signifikan pada penggunaan rokok konvensional. Peningkatan setiap satu botol per bulan akan meningkatkan konsumsi rokok konvensional sebesar 0.5395122 batang. $\boldsymbol{a}_{3}$ sebesar bahwa 0.00000391 pada $X_{3}$ menunjukkan tingkat pengeluaran untuk konsumsi rokok elektronik berpengaruh negatif tetapi tidak signifikan pada penggunaan rokok konvensional. Setiap bertambahnya pengeluaran sebesar 1 rupiah akan mengurangi konsumsi sebesar 0.00000391 batang atau setiap terjadi peningkatan pengeluaran untuk membeli cairan rokok elektronik sebesar $\mathrm{Rp}$ 100.000 per bulan akan mengurangi konsumsi rokok sebesar 0.391 batang per hari. $\boldsymbol{a}_{4}$ sebesar bahwa 5.169504 pada X4 menunjukkan bahwa persepsi konsumen yang beranggapan bahwa penggunaan rokok elektronik lebih sehat di bandingkan rokok konvensional akan mengurangi konsumsi rokok konvensional sebesar 5.169504 batang per hari. Pada tabel 3 juga ditunjukkan bahwa R-squared adalah sebesar 0.2718. Hal ini menunjukkan bahwa variabel-variabel dapat menjelaskan model sebesar 27.18 \% sedangkan sisanya sebesar $72.82 \%$ dijelaskan variabel di luar model tersebut.

Tabel 4 . Deskripsi Statistik

\begin{tabular}{|c|c|c|c|c|}
\hline & $\mathrm{X}_{1}$ & $\mathrm{X}_{2}$ & $\mathrm{X}_{3}$ & $\mathrm{Y}$ \\
\hline Max & 36.00 & 7.00 & $1,155,000$ & 12.00 \\
\hline Min & 0.00 & 0.00 & 40,000 & 0.00 \\
\hline Average & 11.50 & 2.13 & 298,895 & 2.82 \\
\hline Median & 12.00 & 2.00 & 240,000 & 2.00 \\
\hline Std Deviasi & 6.42 & 1.36 & 214,230 & 3.67 \\
\hline
\end{tabular}

Sumber : Hasil Wawancara

Tabel 4 merupakan deskripsi statistik dari variabel-variabel yang digunakan di model penelitian ini kecuali $\mathrm{X}_{4}$ yang merupakan persepsi mengenai apakah penggunaan rokok elektronik lebih sehat atau tidak karena nilainya adalah o dan 1. Tabel 4 di atas menunjukkan bahwa untuk penggunaan rokok konvensional sebelum menggunakan rokok elektronik adalah sebanyak 36 batang per hari dan setelah menggunakan rokok elektronik hanya sebesar 12 batang per hari. Tabel 4 juga menunjukkan bahwa rata-rata konsumen menggunakan rokok konvensional adalah sebanyak 11.50 batang sebelum menggunakan rokok elektronik dan menjadi 2.82 batang setelah menggunakan rokok elektronik. Data survey menunjukkan bahwa terdapat konsumen rokok elektronik yang menghabiskan 7 botol cairan rokok elektronik dalam 1 bulan dan terdapat konsumen yang menghabiskan hingga Rp 1,155,000 untuk konsumsi rokok elektronik. Rata-rata konsumsi cairan rokok elektronik adalah sebanyak 2.13 botol per bulan. Rata-rata pengeluaran rokok elektronik adalah sebesar Rp. 298,895 dan pengeluaran minimum Rp. 40,000.

\section{KESIMPULAN}

Penelitian ini menunjukkan bahwa hanya terdapat dua variabel independen yang berpengaruh signifikan terhadap variabel dependen yaitu jumlah konsumsi rokok konvensional sebelum menggunakan rokok elektronik/ hari (batang) dan persepsi apakah menggunakan rokok elektronik lebih sehat dibandingkan rokok konvensional. Dari 4 variabel dependen yang digunakan dalam penelitian ini, variabel $\mathrm{X}_{4}$ yaitu persepsi mengenai penggunaan rokok elektronik lebih sehat ternyata yang paling banyak mengurangi jumlah konsumsi rokok konvensional sebanyak 5 batang per hari. Sebenarnya diperlukan penelitian yang jelas yang bisa dilakukan oleh pemerintah atau lembaga kesehatan terkait mengenai hal ini dan 
memberitahukan hal yang benar mengenai rokok elektronik. Tingkat pengeluaran untuk rokok elektronik juga sebenarnya berpengaruh pada pengurangan konsumsi rokok elektronik tetapi tidak signifikan. Sedangkan untuk jumlah konsumsi cairan rokok elektronik ditemukan tidak mengurangi konsumsi rokok konvensional

\section{DAFTAR PUSTAKA}

Bam, T., Bollow, W., Berezhnova, L., Jackson-Moris, A., Jones, A., \& Latif, E. (2014). Position Statement on Electronic Cigarette or Electronic Nicotine Delivery Systems. Int J Tuberc Lung Dis. 18(1) :5-7.

Egbe, C. O., Petersen, I., \& Weitz, A. M. (2016). Knowledge of the Negative Effects of Cigarette Smoking on Health and Well-Being among Southern Nigerian Youth. International Journal of Social Science and Humanity, Vol.6, No.3.
Elter, J. (2010). Electronic Cigarette : A Survey of Users. BMC J Public Health. $10: 231$.

Hon, L. (2013). Patent 8393331 B2 Electronic Atomization Cigarette.

Sanford, Z., \& Goebel, L. (2014). E-Cigarettes : An Up to Date Review and Discussion of the Controversy. West Virginia Medical Journal 2014;110(4) :105.

US Department of Health and Human Services. (2016). E-Cigarette Use Among Youth and Youth Adults : A Report of the Surgeon General. Public Health Service: Office of the Surgeon General.

WHO. (2017). WHO Report on the Global Tobacco Epidemic, Country Profile : Indonesia.

William, M., Trtchounian, A., \& Talbot, P. (2010). Conventional and Electronic Cigarette Have Different Smoking Characteristics. Nicotine Tobacco Res. 12 : 905-912. 